\title{
Paranaella luquei gen. et sp. n. (Monogenea: Microcotylidae), a new parasite of Brazilian catfishes
}

\author{
Anna Kohn ${ }^{1,2}$, Maria de Fatima D. Baptista-Farias ${ }^{1}$ and Simone Chinicz Cohen ${ }^{1}$ \\ ${ }^{1}$ Laboratório de Helmintos Parasitos de Peixes, Departamento de Helmintologia, Instituto Oswaldo Cruz, Av. Brasil 4365, \\ 21045-900, Rio de Janeiro, RJ, Brasil; \\ ${ }^{2}$ Research fellow I-A from "Conselho Nacional de Desenvolvimento Científico e Tecnológico - CNPq"
}

Key words: Monogenea, Microcotylidae, Paranaella luquei, catfishes, Paraná River, Brazil

\begin{abstract}
Paranaella, a new microcotyline monotypic genus, is erected to accommodate Paranaella luquei sp. n., parasite of gill filaments from Hypostomus sp., Hypostomus regani (Ihering) and Rhinelepis aspera Spix et Agassiz (Loricariidae) from the Paraná River, Brazil. The new genus is most closely related to Microcotyle Van Beneden et Hesse, 1863, Diplostamenides Unnithan, 1971 and Solostamenides Unnithan, 1971. From Microcotyle it differs mainly by having the genital atrium formed by a muscular ring with a concentric row of numerous elongate and straight spines; from Diplostamenides it can be distinguished by the unarmed and not differentiated cirrus and from Solostamenides it differs by the single vaginal pore and absence of larval hooks.
\end{abstract}

Based on the male terminalia and on general distribution or absence of armature, Unnithan (1971) proposed a systematic partition of Microcotylidae, with 4 subfamilies and 18 genera. Mamaev (1986) presented a taxonomical composition of the Microcotylidae with 8 subfamilies and 39 genera.

Despite the large number of microcotylid species reported from other geographical localities, only 15 species in 9 genera have been reported in South America (Kohn and Cohen 1998, Kohn and Paiva 1999), 14 from marine and one from brackish water fishes.

During recent studies on the helminth fauna of fishes from the freshwater reservoir of the hydroelectric power station of Itaipu, Paraná River, a new species of a new genus of Microcotylinae was found on the gills of two different genera of catfishes.

\section{MATERIALS AND METHODS}

Fishes from the reservoir of Itaipu Hydroelectric Power Station were collected with nets and kept alive until examination. One Hypostomus regani (Ihering) collected in 1992 and seven in 1995 were identified by Dr. Okada from "Universidade de Maringá, Paraná"; seven specimens of Hypostomus sp. and eighteen of Rhinelepis aspera Spix et Agassiz examined in 1999 were identified by Dr. Ferreira de Moraes Junior and Dr. Nunan from "Museu Nacional, Rio de Janeiro". The methodologies used for light and scanning electron microscopies were described in Kohn and Cohen (1996) and in Kohn et al. (1994). Light micrographs were made using a scanning laser confocal microscope Zeiss LMS 410. Measurements were made using a calibrated filar micrometer and are given in micrometers unless otherwise stated, as the range with the mean in parentheses.
Holotype, paratypes and voucher specimens are deposited in the Helminthological Collection of the Oswaldo Cruz Institute, Rio de Janeiro, Brazil (CHIOC) and one paratype in the Institute of Parasitology, Academy of Sciences of the Czech Republic, České Budějovice, Czech Republic (ASCR).

\section{RESULTS}

Family M i c r o c o t y 1 i d a e Taschenberg, 1879 Subfamily Mi c r o c ot y 1 i n a e Monticelli, 1892

\section{Paranaella gen. $\mathrm{n}$.}

\section{Diagnosis}

Body lanceolate. Haptor subsymmetrical with numerous clamps, arranged into sub-equal rows. Clamps of microcotylid type, similar in shape. Hooks absent. Paired buccal suckers unarmed, with septum. Intestinal crura ramified, co-extensive with vitellaria, extending into haptor. Testes numerous, postovarian. Cirrus not differentiated. Genital atrium a muscular ring with numerous long, straight spines disposed in two levels of a concentric row. Ovary tubular, anteriorly folded back on itself. Eggs with a long polar filament. Vagina single, mid-dorsal, unarmed. Vitellaria may extend into haptor. Parasites of freshwater fishes.

$\mathrm{T}$ y p e s p e c i e s: Paranaella luquei sp. $\mathrm{n}$.

E t y molog y: The generic name refers to the type locality at the Paraná River.

\section{Paranaella luquei sp. n.}

Figs. 1-8

Description: Based on 15 mature whole-mounted worms. Body elongate, $2.7-8.1 \mathrm{~mm}(5.9 \mathrm{~mm})$ in total length, $0.8-1.9 \mathrm{~mm}(1.3 \mathrm{~mm})$ in maximum width at level of ovary. Haptor distinguished from body, triangular, lateral margin well developed in its anterior part, 
tapering posteriorly, 0.96-2.4 $\mathrm{mm}(1.3 \mathrm{~mm})$ long. Clamp structure typical of the Microcotylidae (Yamaguti 1963); clamps arranged in two sub-equal rows: 33 to 41 in right side and 29 to 35 in left side; similar in shape, slightly dissimilar in size; middle clamps larger than anterior and posterior ones. Anterior clamps 48-116 (87) wide, 36-72 (50) high; median clamps 80-120 (97) wide, 35-72 (55) high; posterior clamps 60-102 (78) wide, 20-60 (48) high. Hooks absent. Pigment granules dispersed through the regions occupied by the vitellaria; a few groups of pigmented granules between the pharynx and the genital atrium. Buccal organs 60-117 (97) long, 70-123 (77) wide, unarmed, provided with a septum, buccal cavity leading to muscular oval pharynx, 60-101 (88) long, 60-96 (70) wide. Oesophagus thinwalled, ramified, bifurcating anterior to genital atrium. Intestine ramified, co-extensive with vitellaria, extending to haptor. Testes 13-27 (19) in number, situated in postovarian intercaecal field, not extending into haptor. Vas deferens passing anteriorly medially as sinuous tube greatly swollen with sperm, opening in genital atrium. Cirrus not differentiated. Well-developed prostatic glands in anterior region of body, posterior to genital atrium. Genital atrium 120-210 (162) long, 140219 (180) wide, immediately posterior to gut bifurcation, with well-developed radial musculature, with approximated 100 spines, similar in shape, arranged in two different levels of a concentric ring; spines 15-30 (26) long, straight, with bulbous bases. Ovary median, pretesticular, irregularly tubular, with long coiled posterior part, anteriorly folded back on itself. Oviduct a long sinuous tube, running posteriorly from ovary, joining genitointestinal canal and common vitelloduct, turning forward to ootype, with small filiform shell glands (Mehlis' gland). From ootype the uterus runs anteriorly and medially as uncoiled tube, opening into genital atrium. Vaginal pore, median, dorsal, about $1 \mathrm{~mm}$ from anterior extremity. Vaginal canal short, dividing posteriorly into two arms, each opening into a vitelloduct. Vitelloducts run posteriorly and join to form the median common vitelloduct, opening into oviduct. Eggs oval, operculated, 336-450 (399) long, 90-180 (151) wide, with very long coiled filament. Vitelline glands well developed, extending posteriorly from region of genital atrium into haptor.

T y p e h o s t: Hypostomus sp. (Loricariidae); one specimen, MNRJ 19006, deposited in the collection of the "Museu Nacional do Rio de Janeiro".

$\mathrm{O} t \mathrm{~h}$ e $\mathrm{r}$ h o s t s : Rhinelepis aspera Spix et Agassiz, 1829 (Loricariidae) (one specimen, MNRJ 19007, deposited in the collection of the "Museu Nacional do Rio de Janeiro") and Hypostomus regani (Ihering, 1905) (Loricariidae).

S i t e : Gill filaments.

T y p e 1 o c a 1 i t y : Itaipu Hydroelectric Power Station reservoir, Paraná River, Paraná State, Brazil.

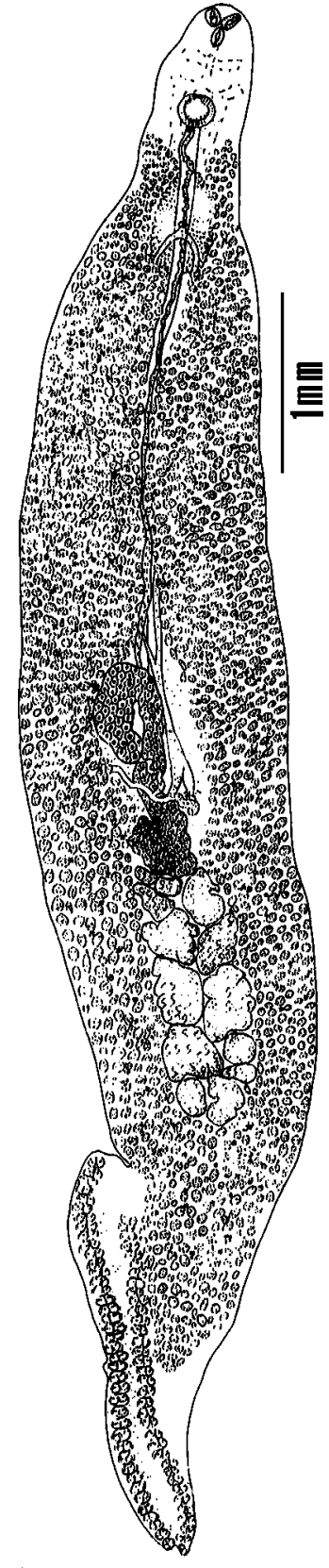

Fig. 1. Paranaella luquei sp. n. Holotype, ventral view.

T y p e m a t e r i a 1: CHIOC: holotype No. 33.954 a and paratypes No. 33.954 b-i, voucher specimens $33.955 a-b$, 33.956, 33.957, 34.203 a-b, 34.204 a-b. ASCR: paratype No. M-360.

P r e v a 1 e n c e : 1/7 Hypostomus sp. collected in 1999, 1/18 Rhinelepis aspera collected in 1999 and 4/8 Hypostomus regani collected in 1992 and 1995.

I $\mathrm{n}$ t e $\mathrm{n} \mathrm{s}$ i t y of i n f e c t i o n : Hypostomus sp.: 6; Hypostomus regani: 1-8; Rhinelepis aspera: 2.

E t y m o lo g y: The new species is named in honour of Dr. José Luis Luque (UFRRJ, Rio de Janeiro), for his contribution to fish parasitology in South America. 

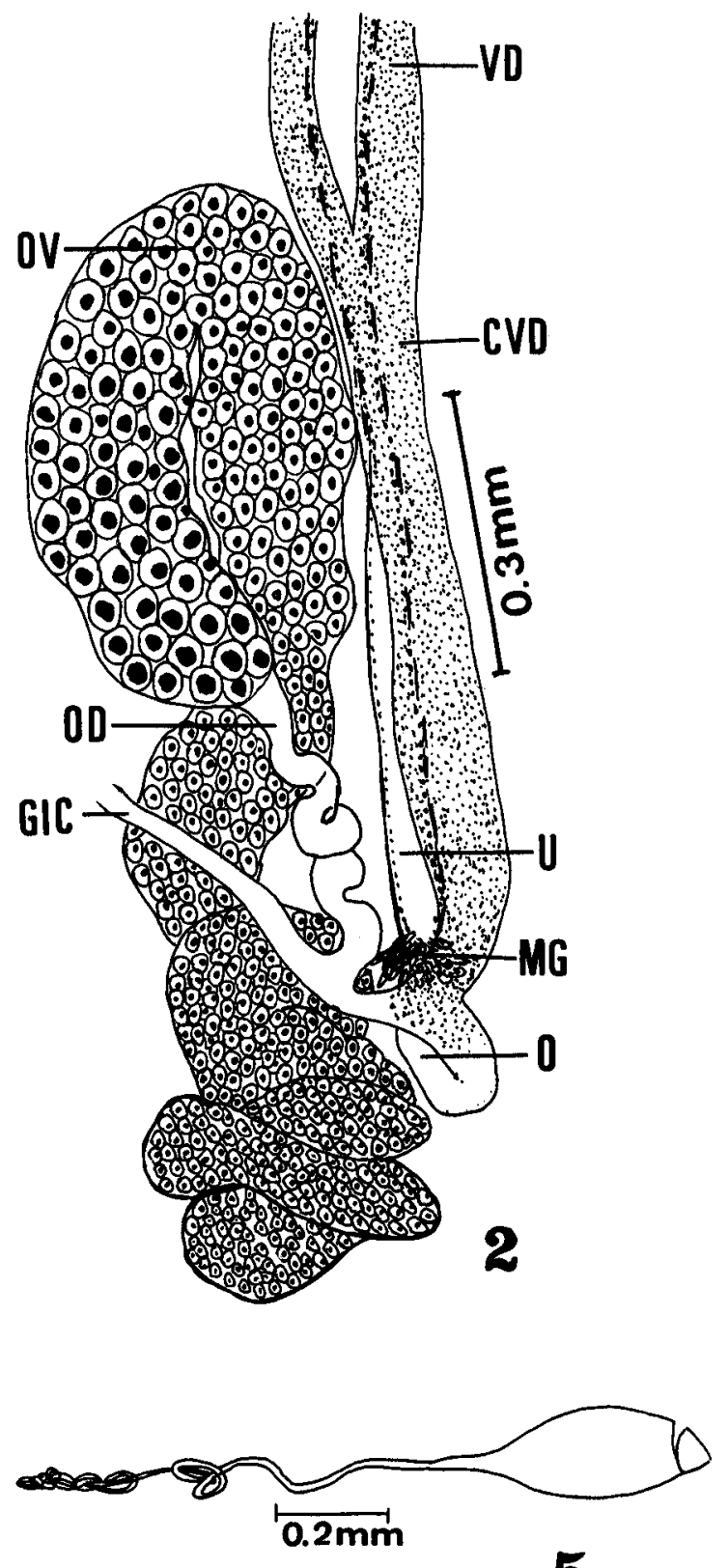

5
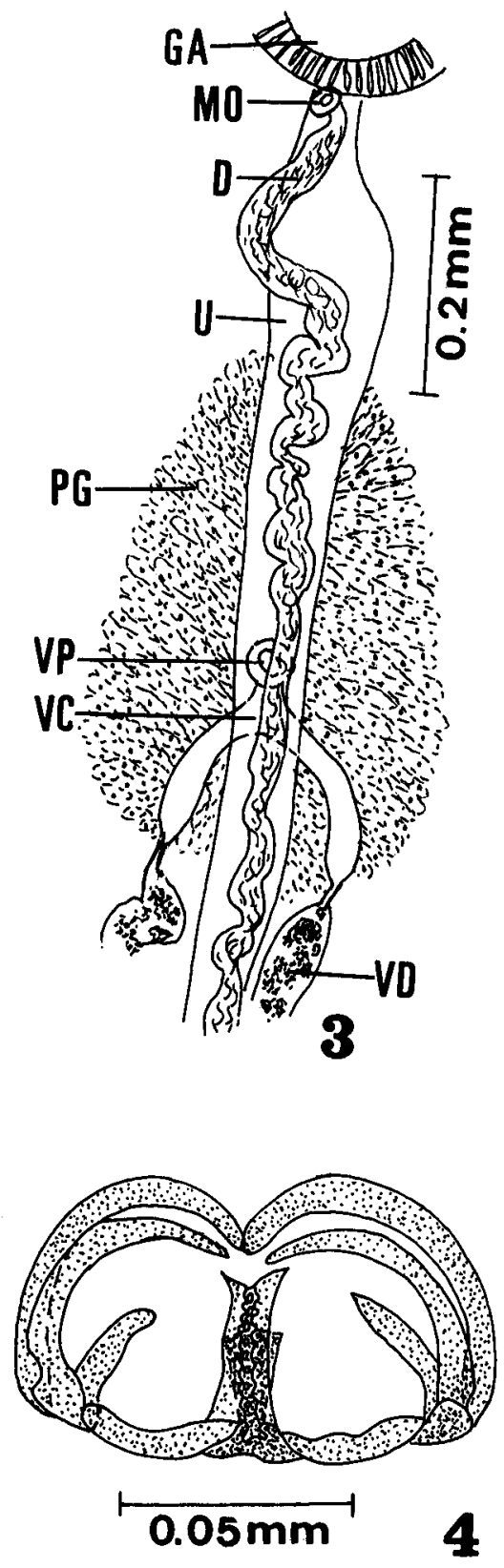

Figs. 2-5. Paranaella luquei sp. n. Figs. 2, 3. Ventral view of reproductive system. Fig. 4. Clamp. Fig. 5. Egg. CVD - common vitelloduct; D - vas deferens; GA - genital atrium; GIC - genito-intestinal canal; MG - Mehlis' gland; MO - male genital opening; O - ootype; OD - oviduct; OV - ovary; PG - prostatic glands; U - uterus; VC - vaginal canal; VD - vitelloduct; VP vaginal pore.

\section{DISCUSSION}

By the symmetrical haptor, genital atrium armed, cirrus unarmed and one vagina, the new monotypic genus Paranaella belongs to Microcotylinae. Of the genera of this subfamily, it is most closely related to Microcotyle Van Beneden et Hesse, 1863, Diplostamenides Unnithan, 1971 and Solostamenides Unnithan, 1971. From Microcotyle it differs mainly by having the genital atrium formed by a muscular ring with a concentric row of numerous elongate and straight spines, instead of the typical genital atrium armed with small and dispersed spines; from Diplostamenides it can be distinguished by the unarmed and not differentiated cirrus and from Solostamenides it differs by the single vaginal pore and absence of larval hooks.

In Microcotylidae, few genera present representatives on fresh and brackish water fishes as Diplostamenides 

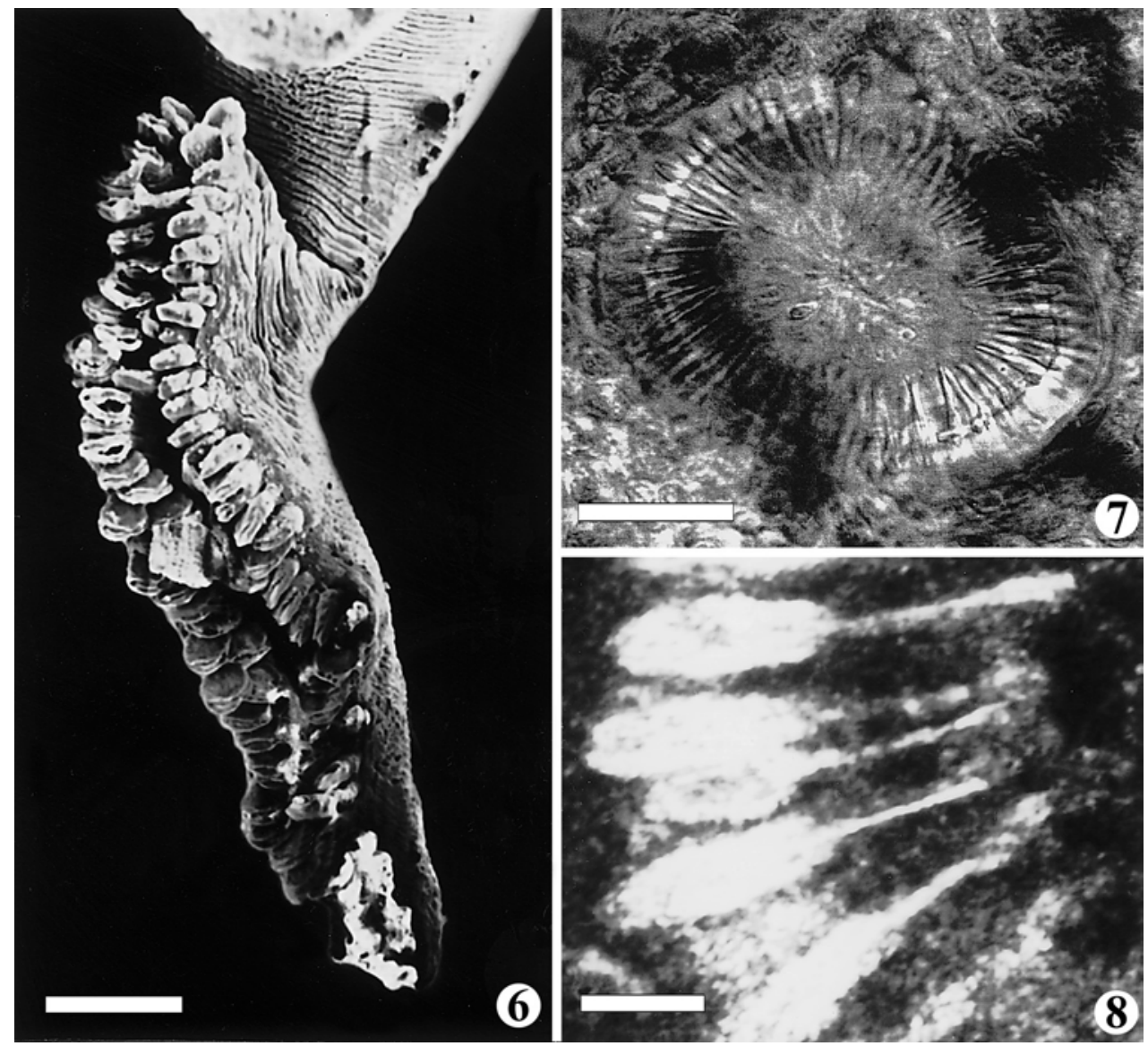

Figs. 6-8. Paranaella luquei sp. n. Fig. 6. Haptor (SEM). Fig. 7. Genital atrium with spines. Scanning laser confocal micrograph (SLCM). Fig. 8. Spines of genital atrium (SLCM). Scale bars: Fig. $6=100 \mu \mathrm{m}$; Fig. $7=50 \mu \mathrm{m}$; Fig. $8=10 \mu \mathrm{m}$.

spinicirrus (MacCallum, 1918), Diplostamenides eriensis (Bangham et Hunter, 1936), Solostamenides pseudomugilis (Hargis, 1956) and Metamicrocotyla macracantha (Alexander, 1954).

The first report of a member of the family Microcotylidae from a freshwater fish was that of Diplostamenides spinicirrus, described originally in the genus Microcotyle by MacCallum (1918) from the gills of Aplodinotus grunniens (Sciaenidae). It was also reported from the same host by Bangham and Hunter (1936), Linton (1940), Remley (1942) and Joy (1988) from the United States and by Bravo-Hollis and Jiménez (1983) from Mexico. Another species, D. eriensis (Bangham et Hunter, 1936) was described from $A$. grunniens from Lake Erie.

Metamicrocotyla macracantha was reported in South America as a marine species from the genus Mugil (Mugilidae) from the coasts of Chile (Oliva and Munoz 1985, Fernandez 1987), Peru (Tantalean 1974, Tantalean et al. 1982, Luque 1994) and Venezuela (Conroy et al. 1985); in Brazil it was reported by Kohn et al. (1994) from Mugil liza from the brackish waters from "Canal de Marapendi", Rio de Janeiro.

According to Fletcher and Whittington (1998) freshwater fishes are defined as those that spend a large proportion of their lives in freshwater, explaining the inclusion of Metamicrocotyla macracantha, Solostamenides pseudomugilis and two unidentified species of Microcotylidae from Mugil cephalus in a parasite-host checklist for Monogenea from freshwater fishes in Australia.

The fishes of the genera Hypostomus and Rhinelepis are found only in freshwater and $P$. luquei was collected in different years and from different species of catfishes from the Paraná River, characterising the parasitism of another species of Microcotylidae in freshwater fishes.

Acknowledgements. The authors are grateful to Dr. Delane Kritsky (Idaho State University) for the critical review of an earlier version of this manuscript; to Dr. Carla Canzi and "Diretoria de Coordenação da Usina Hidrelétrica de Itaipu Binacional" for the facilities offered to examine the fishes; to Drs. Ortrud M. Barth, Henrique Lenzi, Marcelo P. Machado and Bruno S. Vale (Fundação Oswaldo Cruz)) for technical assistance; to Drs. Albina Gaevskaya (Institute of Biology of the Southern Seas) and Boris I. Lebedev (Institute of Biology and Pedology), for providing literature; to Drs. Edson Okada ("Universidade de Maringá"), Decio Ferreira de Moraes Junior and Gustavo Wilson Nunan (Universidade Federal do Rio de Janeiro) for the identification of the hosts; to the anonymous referees for suggestions. 


\section{REFERENCES}

BANGHAM R.V., HUNTER G.W. 1936: Studies on fish parasites of Lake Erie. III. Microcotyle spinicirrus Mac Callum, 1918 char. emend. and M. eriensis sp. nov. Trans. Am. Microsc. Soc. 55: 334-339.

BRAVO-HOLLIS M., JIMÉNEZ F. 1983: Redescripción de Microcotyle spinicirrus MacCallum, 1918. An. Inst. Biol. Univ. Nac. Autón. Méx. Ser. Zool. 53: 19-26.

CONROY G., CONROY D.A., RODRIGUEZ A. 1985: A note on the occurrence of "coiled" Metamicrocotyla macracantha on the gills of silver mullet (Mugil curema) from Chichiriviche, Venezuela. Bull. Eur. Assoc. Fish Pathol. 5: 66.

FERNANDEZ J.B. 1987: Los parasitos de la "lisa" Mugil cephalus L., en Chile: sistematica y aspectos poblacionales (Perciformes: Mugilidae). Gayana Zool. 51: 3-58.

FLETCHER A.S., WHITTINGTON I.D. 1998: A parasitehost checklist for Monogenea from freshwater fishes in Australia, with comments on biodiversity. Syst. Parasitol. 41: 159-168.

JOY J.E. 1988: Monthly length class frequencies of Microcotyle spinicirrus (Monogenea: Microcotylidae) from the freshwater drum, Aplodinotus grunniens, in West Virginia. Proc. Helminthol. Soc. Wash. 55: 246-251.

KOHN A., COHEN S.C. 1996: Report of two Monogenea in marine fishes from the coast of Rio de Janeiro. Neotropica 42: 29-32.

KOHN A., COHEN S.C. 1998: South American Monogenea list of species, hosts and geographical distribution. Int. J. Parasitol. 28: 1517-1554.

KOHN A., COHEN S.C., BAPTISTA-FARIAS M.F.D. 1994: Redescription of the morphology of Metamicrocotyla macracantha (Alexander, 1954) Koratha, 1955 (Monogenea, Microcotylidae). Syst. Parasitol. 27: 127-132.

KOHN A., PAIVA M.P. 1999: Fishes parasitised by Monogenea in South America. Vol. Comem. de los 70 Años del Inst. Biol. Univ. Natl. Autón. Méx. pp. 9-44.
LINTON E. 1940: Trematodes from fishes mainly from the Woods Hole region, Massachusetts. Proc. U.S. Natl. Mus. 88: 1-172.

LUQUE J.L. 1994: Dinámica poblacional de Metamicrocotyla macracantha (Monogenea: Microcotylidae) parásito de Mugil cephalus (Pisces: Mugilidae) en la costa central peruana. Rev. Biol. Trop. 42: 733-735.

MacCALLUM G.A. 1918: Notes on the genus Telorchis and other trematodes. Zoopathologica 1: 81-98.

MAMAEV Y.L. 1986: The taxonomical composition of the family Microcotylidae Taschenberg, 1879 (Monogenea). Folia Parasitol. 33: 199-206.

OLIVA M.E., MUNOZ M.A. 1985: Microcotyloidea (Platyhelminthes: Monogenea) en peces marinos de la zona de Antofagasta. Estud. Oceanol. 4: 1-8.

REMLEY L.W. 1942: Morphology and life history studies of Microcotyle spinicirrus MacCallum, 1918, a monogenetic trematode parasitic on the gills of Aplodinotus grunniens. Trans. Am. Microsc. Soc. 61: 141-155.

TANTALEAN M.V. 1974: Monogeneos de la familia Microcotylidae Taschenberg, 1879, parasitos de peces del mar peruano, con descripcion de una especie nueva. Biota 10: $120-127$.

TANTALEAN M.V., CARBAJAL C.G., MARTINEZ R.R., HUIZA F.A. 1982: Helmintos parasitos de peces marinos de la costa peruana. Naturaleza, Ciencia y Tecnologia Local, Ser. Div. Cient. 1: 40.

UNNITHAN R.V. 1971: On the functional morphology of a new fauna of Monogenoidea on fishes from Trivandrum and environs. Part IV. Microcotylidae sensu stricto and its repartition into subsidiary taxa. Am. Midl. Nat. 85: 366398.

YAMAGUTI S. 1963: Systema Helminthum: Monogenea and Aspidocotylea. Vol. IV. Interscience Publishers, New York, 699 pp.

Accepted 5 April 2000 